\title{
Durability to Chemical Attack by Acids of Epoxy Microconcretes by Comparison to Cementitious Ones
}

\author{
Elhem Ghorbel and Murhaf Haidar \\ University of Cergy-Pontoise, 5 Mail Gay-Lussac, Neuville sur Oise, 95031 Cergy-Pontoise Cedex, France \\ Correspondence should be addressed to Elhem Ghorbel; elhem.ghorbel@u-cergy.fr
}

Received 10 May 2016; Accepted 16 August 2016

Academic Editor: Sertong Quek

Copyright ( 2016 E. Ghorbel and M. Haidar. This is an open access article distributed under the Creative Commons Attribution License, which permits unrestricted use, distribution, and reproduction in any medium, provided the original work is properly cited.

\begin{abstract}
This research deals with the durability of micropolymer concrete (MPC) obtained by mixing an epoxy resin with fine and coarse sand particles. In particular the resistance of the micropolymer concrete to chemical solutions (citric acid $\mathrm{C}_{6} \mathrm{H}_{8} \mathrm{O}_{7}$, sulfuric acid $\mathrm{H}_{2} \mathrm{SO}_{4}$, and hydrochloric acid $\mathrm{HCl}$ ) is investigated and compared to this of Portland cement microconcrete. Two MPC are tested. The first is formulated with $9 \%$ mass fraction of epoxy polymer whereas calcareous fillers have been incorporated in the second formulation in order to reduce the percentage of the epoxy binder. It is shown that a microconcrete designed with $7 \%$ of epoxy, $10 \%$ of fillers, and $83 \%$ of aggregates is characterized by higher physical and mechanical properties than those of the MPC formulated with $9 \%$ of epoxy binder. The mechanical properties of the resulting materials after their exposure to the three selected acid solutions at different durations were studied through compressive, three points bending and ultrasonic wave propagation tests. The obtained results are compared to those of microcement concretes (MCC) tested under the same conditions as MPC. The results show that both microepoxy polymer concretes exhibit better mechanical properties and highest resistance to chemical attack than the microcement concrete.
\end{abstract}

\section{Introduction}

The durability of any material depends on the environment to which it was exposed. Hence, for polymer concretes UV radiation, temperature, rain, and wind represent the most common environments [1]. In general, the mechanical performance of any composite material strongly depends on the nature of the matrix or binder (thermoplastic, metallic, ceramic, ...), the reinforcement (sand, gravels, filler, fibers, ...), and the quality of the adhesion between the components. The polymer concrete (PC) is made by replacing a part or total cement hydrate binder of conventional mortar or concrete with polymers or by strengthening the cement hydrate binder with polymers [2]. Polymer mortars have been mainly used for industrial flooring and retouching of damaged concrete structures and underground pipes and several precast products like acid tanks, drains, highway median barriers, and so forth [3]. Its compounds have become a good choice for the civil construction sector, in developed countries, particularly in applications where high strength, fast cure, and durability are required [4]. Many studies have been achieved in this field; most of them are dedicated to optimize the formulations of polymer mortar, named PM, to reduce the cost and to improve the mechanical properties [5]. However, few works deal with the resistance of polymer concrete to aggressive chemical agents especially by comparison to those of Portland cement concretes.

The first investigations on the behavior of PM after exposure to various chemical solutions with different $\mathrm{pH}$ levels were published in 1995 [6]. The authors concluded that immersing polyester mortars during one month conduct to a decrease of their strengths. This decrease is enhanced by the increase of the $\mathrm{pH}$ level.

In 2002 Ribeiro et al. [7] published a work on the analysis of chemical resistance of epoxy and unsaturated polyester polymer mortars to aqueous solutions of sulphuric acid and sodium chloride. For both formulations, the resin content was $20 \%$ by weight of mortar. The chemical resistance was evaluated through the evolution of bending strengths and mass change after exposure to acid solutions for periods of 
time less than 84 days. They showed that the flexural strength of epoxy PC is slightly affected by the immersion in the sulphuric acid and sodium chloride solutions. Indeed, the maximum flexural strength decrease occurring for epoxy PM was approximately $8 \%$ against $30 \%$ in the case of polyester PM. Moreover a very small water uptake is observed.

In 2004, Gorninski et al. [8] produced polymer mortars using orthophthalic and isophthalic polyester mixed with river medium sand and fly ash. The concentrations of polymer used were $12 \%$ of orthophthalic polyester and $13 \%$ of isophthalic polyester by weight of the dry materials. The results demonstrated that the addition of fly ash to PM reduced voids and increased the packing of the aggregateash skeleton resulting in an increase in compressive strength of PM as the fly ash content increases. In a separate work Gorninski et al. [4] confirmed that the use of fly ash in polymer mortar prepared with the same concentration of orthophthalic and isophthalic resins improves the compressive and flexural strengths and the durability conducted under chemical attack. They showed that all the PM compositions exhibited higher strength values when compared to Portland cement mortars with silica fume or fly ash and found that the resistance to chemical attack of PM manufactured with both resins is similar. In 2009, Reis [9] studied the influence of chemical degradation on flexural and compressive strength of polymer mortars formulated with a resin content of about $12 \%$ by the total weight of the mortar. He found that the flexural and compressive strengths of the polymer mortar decreased after their immersion in citric acid for less than one week. In 2010, Reis published another work on the fracture properties and elastic modulus of the same epoxy polymer mortar exposed for 7 days to several chemical solutions with $\mathrm{pH}$ varying from 1.2 to 12.8 (distilled water, sulfuric, formic, acetic, lactic acids, sodium hydroxide and sodium chloride) [10]. He noticed an important decrease in the fracture properties, as well as in the modulus of elasticity of the samples exposed to corrosive agents. The visual observations highlight the polymer concrete degradation except for formic and acetic acids. He concluded that the remaining strength values were far higher than those found in the literature dealing with mortars prepared with Portland cement.

In 2013, Golestaneh et al. [11] investigated the chemical resistance of epoxy polymer reinforced with silica powders having particles size less than $1100 \mu \mathrm{m}$. The mortars were exposed to five aggressive environments: sodium hydroxide solution, hydrochloric acid, sulfuric acid, citric acid, and acetic acid with 15,30 , and $60 \%$ concentrations. The rate of chemical degradation (the compressive strength, the weight change, and the appearance of samples) was determined after $7,14,28$, and 56 days of immersion. They concluded that the PC specimens have great chemical resistance except in acetic acid solution with a weight loss of about $31 \%$.

More recently, Heidari-Rarani et al. [12] investigated the splitting tensile strength, fracture toughness, and frost resistance of epoxy polymer concrete (PC) materials. Three different freeze/thaw cycles, chosen according to the climate of Iran, were applied for 7 days. They showed that the fracture toughness and tensile strength of tested PC materials are reduced by increasing the mean temperature values of thermal cycles.

Martínez-López et al. [13] studied the failure of cracked epoxy resin system polymer mortar plates in combined modes I and II. They established a simple mixed-mode failure criterion.

All the literature investigations are concerned with polymer mortars formulated with polymer content higher than $12 \%$ and fine aggregates. Moreover, the reported exposure durations are less than 84 days. No comparison with cementitious material was done. The results reveal that the polymer mortars are more resistant to some chemical attack than the cementitious ones on the basis of literature results.

This investigation focused on polymer concretes dedicated to precast applications so that the amount of the polymeric binder must be reduced to a minimum and consequently the workability will be hard. A previous work [14] performed on the optimization of the formulation of micropolymer concrete, designed as MPC, showed that beyond $9 \%$ epoxy polymer weight ratio, the mechanical and physical properties did not change appreciably. In order to diminish the cost of the polymer concrete, the binder concentrations must be reduced without affecting the mechanical characteristics of MPC which must remain at least equal to those obtained for the conventional MPC manufactured with 9\% of epoxy. To achieve this target, calcareous fillers are introduced in the formulation of MPC manufactured with 7\% of epoxy polymer. Hence, this work deals with two formulations of MPC and one formulation of microcement concrete MCC using the same aggregates. The first MPC, called MPCc, contains $9 \%$ of epoxy polymer weight ratio $\left(m_{p}=9 \%\right), 91 \%$ aggregates weight ratio, while the second one contains $7 \%$ of polymer, different ratios of calcareous fillers and aggregates. The aggregates are fine and coarse sand. The first objective of this study is to find the optimal calcareous fillers ratio providing the better mechanical performances and leading to the definition of a polymer concrete, called MPCm.

The second objective of this work is to assess the durability of MPCc and MPCm when immersed to acid solutions for long durations (6 months) and to compare it with this of MCC exposed to the same aggressive environments. The degradation of microconcretes is measured throughout the evolution of compressive strength, the three points bending strength, the elastic modulus, the mass change, the chemical analysis, and the appearance change.

\section{Materials}

2.1. Resins. Micropolymer concrete formulations were prepared by mixing a commercial epoxy resin and an amine solution with the aggregates. The used epoxy prepolymer is based on Bisphenol A diglycidyl ether resin (DGEBA) with a density of $1.12 \mathrm{gr} / \mathrm{cm}^{3}$ and a viscosity of $1700 \mathrm{MPa} \cdot \mathrm{s}$. The epoxy prepolymer is cured with a cycloaliphatic diamine, 5-amino-1,3,3-trimethylcyclohexylamine characterized by a density of $1.05 \mathrm{gr} / \mathrm{cm}^{3}$ and a viscosity of 420-530 MPa.s. The glass transition temperature, $T_{\mathrm{g}}$, of the cross linked epoxy polymer recorded using differential scanning calorimetry analysis (DSC) with a Mettler TA3000 apparatus (heating rate 

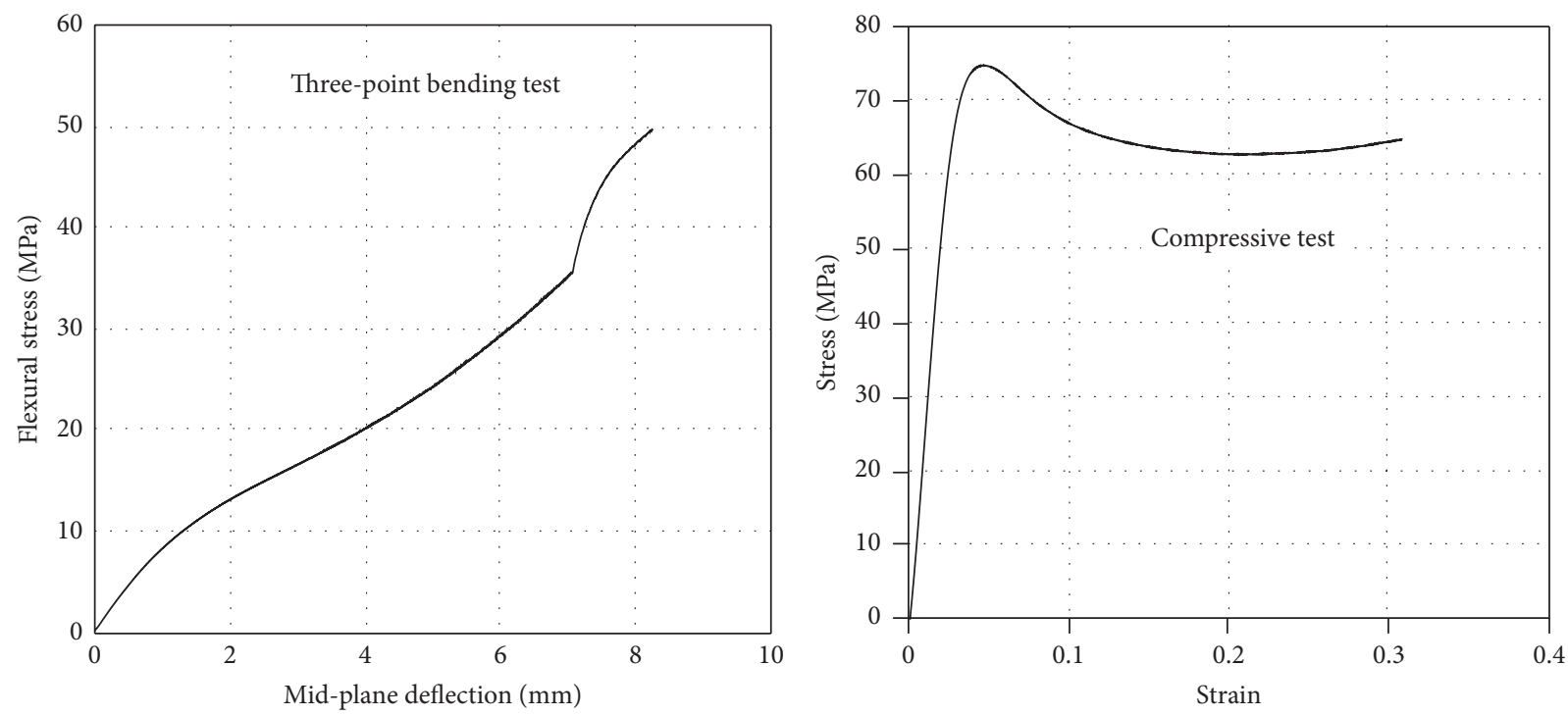

FIgURE 1: Mechanical response of cross linked epoxy polymer.

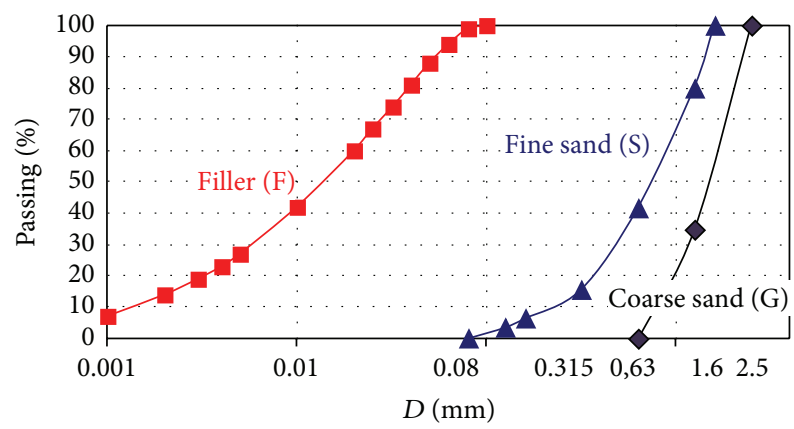

Figure 2: The size distribution of the used filler, sand, and gravel.

$20^{\circ} \mathrm{C} \mathrm{min}^{-1}$ ) is about $93^{\circ} \mathrm{C}$. Hence, it can be considered that the polymer is at the glassy state and its behavior is elastic at room temperature which is the service temperature. Threepoint bending and compressive tests were carried out on the cross linked epoxy polymer at $1 \mathrm{~mm} / \mathrm{min}$ using an Instron 5567 machine. The specimens are cylindrical for compression $(\Phi \times L: 13 \times 26 \mathrm{~mm})$ and prismatic $(40 \times 40 \times 160 \mathrm{~mm})$ for 3 point bending tests. The stress-strain curves are illustrated in Figure 1. A quite linear stress-strain curve is observed up to failure at $50 \mathrm{MPa}$ for bending test while a nonlinear behavior is observed under compression with a maximum stress about $74 \mathrm{MPa}$.

2.2. Aggregates. The aggregates used to manufacture the micropolymer concrete were constituted of fine sand, S, and coarse sand, G, having absolute density of about $2631 \mathrm{~kg} / \mathrm{m}^{3}$ and $2633 \mathrm{~kg} / \mathrm{m}^{3}$, respectively, while the apparent bulk density is equal to 1.729 for $\mathrm{S}$ and 1.518 for $\mathrm{G}$. The X-rays diffraction analysis conducted on aggregates proves that both sand and gravel are siliceous. The particles size distribution of filler, sand, and gravel is shown in Figure 2.

2.3. Filler. To reduce the binder concentrations and consequently the cost of the polymer concrete, the sand $S$ is partially substituted by calcareous filler to produce modified micropolymer concretes designed as MPCm. The calcareous fillers are provided by OMYA SAS and are characterized by a Blaine surface equal to $409 \mathrm{~kg} / \mathrm{m}^{2}$. They were added in the formulation in quantities varying between 5 and $15 \%$ by the total weight of the mortar.

\section{Experimental Program}

Tow micropolymer concretes formulations were prepared by mixing the epoxy resin and amine hardener with the aggregates. The mix design method adopted here is based on the optimization of the packing density of the granular skeleton using the compressible packing model which provides the gravel/sand ratio for the minimum void fraction. The adopted ratio is $\mathrm{G} / \mathrm{S}=0.25$. The procedure of preparation is well described by Haidar et al. [14]. Besides, a formulation of MCC was investigated to compare the behavior after chemical attack of the MPC and the MCC.

The materials used to prepare the MCC are a CEM I $52.5 \mathrm{~N}$ Portland cement and the same aggregates compared to those used for manufacturing MPC. The MCC was designed with respect to the environmental exposure class XA2 according to the European Standard EN 206-1. Hence to cover the requirements of the exposure class, the cement content of the mix is taken equal to $350 \mathrm{~kg} / \mathrm{m}^{3}$, the water cement ratio, $\mathrm{W} / \mathrm{C}$, is about 0.5 , and the gravel sand ratio is kept constant $\mathrm{G} / \mathrm{S}=0.25$ leading to an estimated compressive strength, according to the Bolomey formula, of about $45 \mathrm{MPa}$.

Before immersing the samples in chemical solutions, micropolymer concrete samples were fully cured at $23^{\circ} \mathrm{C}$ and $48 \% \mathrm{RH}$ for 28 days and then postcured at $40^{\circ} \mathrm{C}$ for 48 while microcement concrete samples were kept in water at $22^{\circ} \mathrm{C}$ for 28 days and then postcured at $22^{\circ} \mathrm{C}$ for 7 days.

The prismatic specimens, measuring $40 \times 40 \times 160 \mathrm{~mm}$, were molded to perform under the three points bending test while cubical $(40 \times 40 \times 40 \mathrm{~mm})$ and cylindrical $(40 \times$ 
TABLE 1: Acid solutions used for microconcretes exposure.

\begin{tabular}{lcc}
\hline Chemical solution & Type of acid & $\mathrm{pH}$ \\
\hline Sulfuric acid $\left(\mathrm{H}_{2} \mathrm{SO}_{4}\right)$ & Mineral & 0.31 \\
Hydrochloric acid $(\mathrm{HCl})$ & Mineral & 0.16 \\
Citric acid $\left(\mathrm{C}_{6} \mathrm{H}_{8} \mathrm{O}_{7}\right)$ & Organic & 1.51 \\
\hline
\end{tabular}

$80 \mathrm{~mm}$ ) specimens were casted to realize the compressive and the ultrasonic wave's propagation tests, respectively.

3.1. Chemical Attack Procedure. The selected chemical solutions to simulate the aggressive environments were citric acid $\left(\mathrm{C}_{6} \mathrm{H}_{8} \mathrm{O}_{7}\right)$ with a concentration of $2.817 \mathrm{~mol} / \mathrm{L}$, hydrochloric acid $(\mathrm{HCl})$ with a concentration of $11 \mathrm{~mol} / \mathrm{L}$, and sulfuric acid $\left(\mathrm{H}_{2} \mathrm{SO}_{4}\right)$ with a concentration of a $10.16 \mathrm{~mol} / \mathrm{L}$. The $\mathrm{pH}$ of each solution was measured before immersing the samples and after they were removed (Table 1). The severity of all acids is considered as very strong according to EN 206-1.

After fully curing (at $23^{\circ} \mathrm{C}$ and $48 \% \mathrm{RH}$ for 28 days), the samples (the prismatic $40 \times 40 \times 160 \mathrm{~mm}$ for flexure test, the cubical $40 \times 40 \times 40 \mathrm{~mm}$ for compressive test, and the cylindrical $40 \times 80 \mathrm{~mm}(\Phi \times L)$ dedicated to ultrasonic wave's propagation test) were completely immersed in chemical solutions for different durations ranging from 2 weeks to 6 months. They were placed in high density polyethylene tanks; the volume of the chemical solution was three times greater than the volume of the samples in the tank. The first sample was placed $4 \mathrm{~cm}$ from the tank wall; each sample is surrounded by $4 \mathrm{~cm}$ of chemical solution. Before performing the mechanical tests, all the specimens were removed from the chemical solutions and were washed with water in order to remove any corrosion products from their surface. Then, they were oven-dried at $22^{\circ} \mathrm{C}$ for one week and kept at $40^{\circ} \mathrm{C}$ for another one week.

3.2. Mechanical Tests. The ultrasonic wave's propagation test is performed to determine Young's modulus and Poisson's ratio of MPC and MCC by measuring the shear wave velocity $V_{\mathrm{US}_{S}}$ and the pressure wave velocity $V_{\mathrm{US}_{P}}$. The sensor used to measure the pressure waves has a diameter $2.54 \mathrm{~cm}$ and frequency $0.5 \mathrm{MHz}$. The sensor used to measure the shear waves has a diameter $2.54 \mathrm{~cm}$ and a frequency of $1.0 \mathrm{MHz}$. Each test was repeated at least three times.

The 3-point bending and the compressive and the tensile tests were conducted on MPC and MCC specimens after different immersion durations in the acid solutions. All these tests were carried out according to the RILEM CPT PCM2 and PCM8 standard test methods $[15,16]$. The compressive tests are performed at a loading rate of $1.25 \mathrm{~mm} / \mathrm{min}$. Each test is repeated 5 times at least.

\section{Effects of Adding Fillers on the Characteristics of Micropolymer Concretes}

According the work of Haidar et al. [14], the optimum micropolymer concrete, called MPCc, was prepared by mixing $9 \%$ epoxy polymer and $91 \%$ aggregates (sand $\mathrm{S}$ and gravel

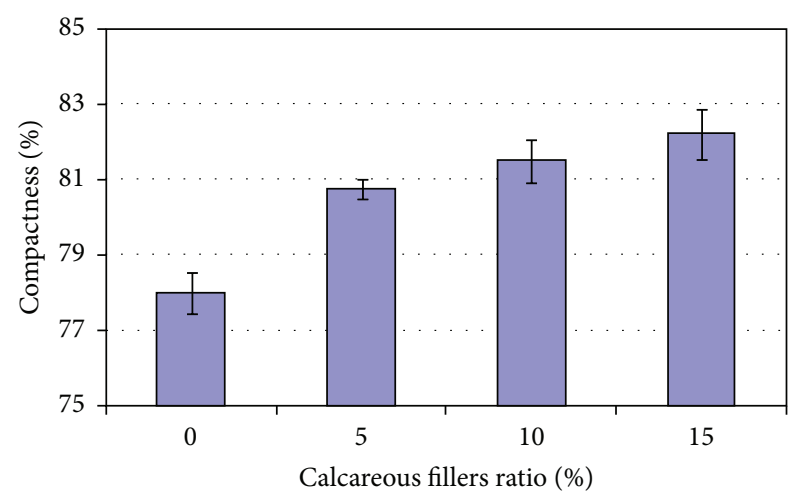

FIGURE 3: Effects of introducing calcareous fillers on the compactness of MPC.

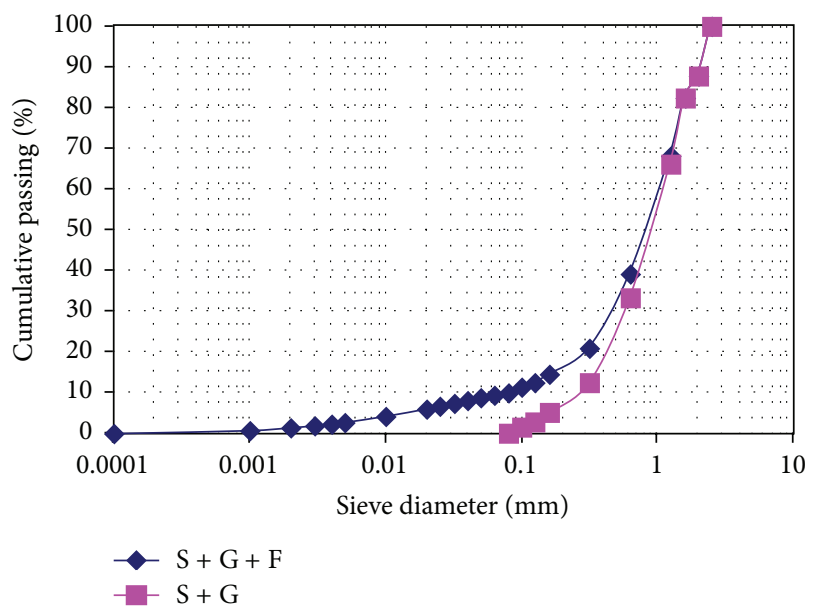

FIGURE 4: Effect of introducing calcareous fillers on the grading distribution of the solid particles.

$\mathrm{G})$ with $\mathrm{G} / \mathrm{S}=0.25$. All the components quantities are given in percentage by the weight of micropolymer concrete.

In order to reduce the polymeric binder content to $7 \%$, calcareous fillers are introduced at 5, 10, and $15 \%$ by weight of the microconcrete (Table 2). The ratio of coarse aggregates to fine by weight, $G /(S+F)$, is kept constant and equal to 0.25 .

The incorporation of calcareous fillers improves the granular mixture compacity because fillers allow filling the voids between aggregates (Figure 3).

Consequently, a decrease of the total porosity, $n(\%)$, as well as of the size of the distributed pores, $d_{c}(\mu \mathrm{m})$, is observed when polymer microconcretes were tested at 21 days using the mercury intrusion porosimeter. Each test was repeated twice on cylindrical samples $(25 \times 25 \mathrm{~mm})$ and the recorded values of total porosity, reduction of porosity (\%), and the most distributed pores are summarized in Table 3.

Moreover, adding calcareous fillers improves the grading distribution of the solid particles (Figure 4). As a consequence, the mechanical strengths are enhanced significantly for filler ratios higher than 5\% (Figure 5) whereas the workability is reduced. These results are in accordance with those of literature [5]. 
TABLE 2: The mix proportions in $\mathrm{kg} / \mathrm{m}^{3}$ of the modified polymer microconcrete formulated with $7 \%$ polymer of the total weight of the mortar.

\begin{tabular}{lccccc}
\hline $\begin{array}{l}\text { Filler weight ratio } \\
m_{F}(\%)\end{array}$ & Epoxy binder & $\mathrm{S}$ & $\mathrm{G}$ & Filler & Density $\left(\mathrm{kg} / \mathrm{m}^{3}\right)$ \\
\hline $0 \%$ & 155 & 1649 & 412 & 0 & 2217 \\
$5 \%$ & 156 & 1552 & 416 & 112 & 2236 \\
$10 \%$ & 158 & 1453 & 420 & 226 & 2256 \\
$15 \%$ & 159 & 1348 & 422 & 340 & 2269 \\
\hline
\end{tabular}
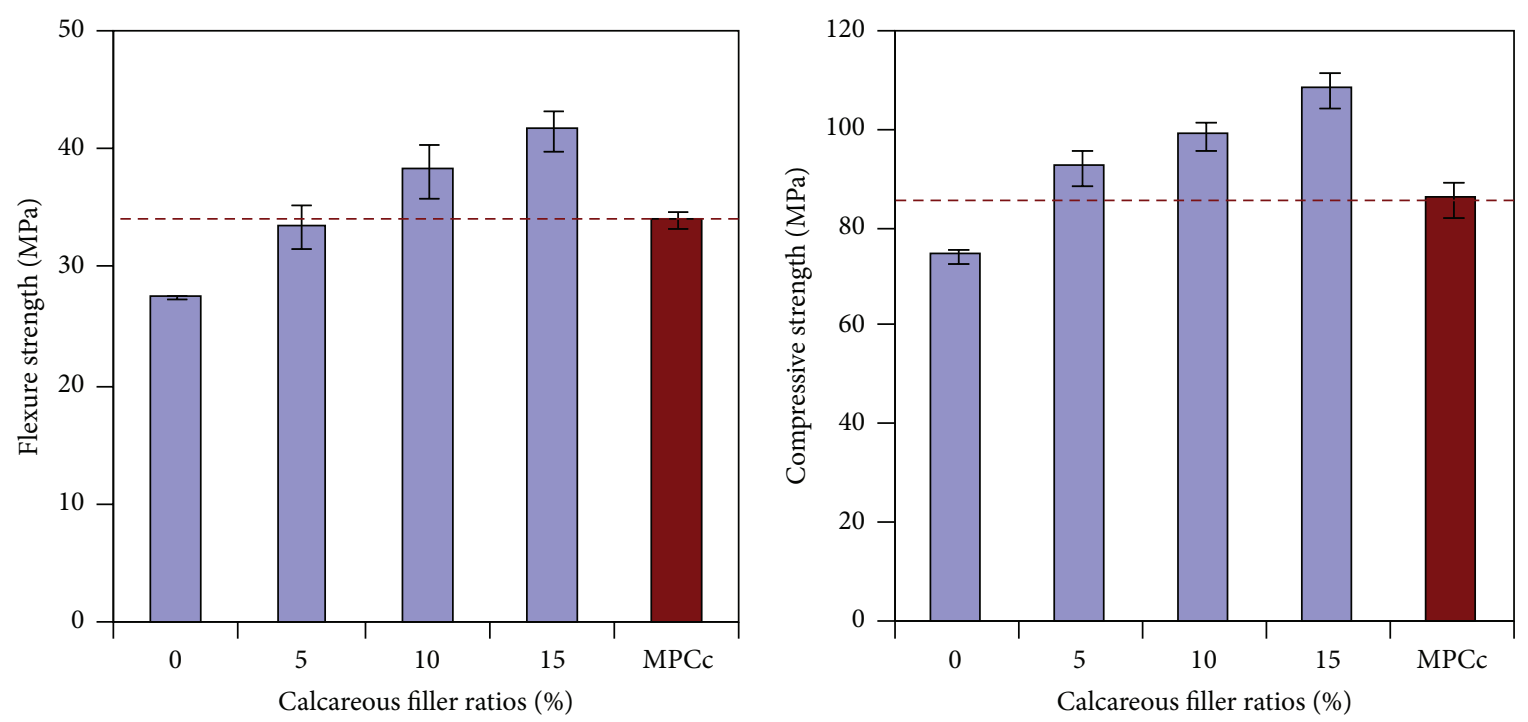

FIGURE 5: Effect of introducing fillers on the mechanical strengths of MPC.

TABLE 3: Effect of introducing calcareous fillers on the porosity parameters of MPC.

\begin{tabular}{lccc}
\hline$m_{F}(\%)$ & $m_{p}(\%)$ & $n(\%)$ & $d_{c}(\mu \mathrm{m})$ \\
\hline 0 & 7 & 1.8 & 0.07 \\
5 & 7 & 1.6 & 0.03 \\
10 & 7 & 1.5 & 0.006 \\
15 & 7 & 1.4 & 0.03 \\
\hline
\end{tabular}

TABLE 4: Designation and composition of the three selected micropolymers under study.

\begin{tabular}{lccc}
\hline & \multicolumn{2}{c}{ Designation } \\
& MPCc & MPCm & MCC \\
\hline $\begin{array}{l}\text { Binder type } \\
\text { Weight ratio }\end{array}$ & Epoxy $\left(m_{p}=9 \%\right)$ & Epoxy $\left(m_{p}=7 \%\right)$ & Cement \\
of filler & $0 \%$ & $10 \%$ & $0 \%$ \\
$\mathrm{G} /(\mathrm{S}+\mathrm{F})$ & 0.25 & 0.25 & 0.25 \\
\hline
\end{tabular}

Moreover, the incorporation of calcareous fillers in the polymer concrete at a ratio of $10 \%$ enhances mechanical strengths without reducing obviously the workability by comparison to MPCc. The called MPCm is the designation of the polymer microconcrete prepared by mixing 7\% epoxy polymer ratio, $10 \%$ calcareous fillers, and $83 \%$ aggregates, with $\mathrm{G} /(\mathrm{S}+\mathrm{F})=0.25$ (Table 4$)$.

The composition of concretes subjected to chemical attack is summarized in Table 5 while their mechanical characteristics prior to durability tests are given in Table 6 . Each value is the average of five values at least.

The strengths of both polymer concretes are higher than those of cement concrete especially under flexure and tension while the elastic properties are quite similar. Introducing fillers and reducing the polymer content enhance the compressive and flexure strength while the other mechanical characteristics remain almost constant (Table 6).

\section{Mechanical Characteristics of Mortars after Exposure to Acid Solutions}

5.1. Modulus of Elasticity. To calculate the modulus of elasticity and Poisson's ratio, the velocities of propagation of the transversal $V_{\mathrm{US}_{S}}$ and longitudinal $V_{\mathrm{US}_{P}}$ waves were measured for MPC and MCC, and then the elastic characteristics were calculated from

$$
\begin{aligned}
\mu & =\rho \times V_{\mathrm{US}_{S}}^{2}, \\
K & =\rho\left(V_{\mathrm{US}_{P}}^{2}-\frac{4}{3} V_{\mathrm{US}_{S}}^{2}\right), \\
\frac{1}{E} & =\frac{1}{9 K}+\frac{1}{3 \mu}, \\
v & =\frac{E}{2 \mu}-1,
\end{aligned}
$$


TABLE 5: Microconcretes mix proportions used in this study.

\begin{tabular}{|c|c|c|c|c|c|c|c|}
\hline \multirow{2}{*}{ Concrete } & \multicolumn{4}{|c|}{$\operatorname{Binder}\left(\mathrm{kg} / \mathrm{m}^{3}\right)$} & \multirow{2}{*}{ Sand $\left(\mathrm{kg} / \mathrm{m}^{3}\right)$} & \multirow{2}{*}{ Gravel $\left(\mathrm{kg} / \mathrm{m}^{3}\right)$} & \multirow{2}{*}{ Filler $\left(\mathrm{kg} / \mathrm{m}^{3}\right)$} \\
\hline & Prepolymer & Hardener & Cement & Water & & & \\
\hline MPCc & 134 & 67 & - & - & 1622 & 406 & - \\
\hline MPCm & 105 & 53 & - & - & 1453 & 420 & 226 \\
\hline MCC & - & - & 350 & 175 & 1469 & 368 & - \\
\hline
\end{tabular}

TABLE 6: Characteristics of MPC and MCC before chemical attack.

\begin{tabular}{lccc}
\hline & MCC & MPCc & MPCm \\
\hline $\begin{array}{l}\text { Density }\left(\mathrm{kg} / \mathrm{m}^{3}\right) \\
\begin{array}{l}\text { Compressibility } \\
\text { modulus }(\mathrm{GPa})\end{array}\end{array}$ & 2229 & 2228 & 2256 \\
$\begin{array}{l}\text { Elasticity modulus } \\
(\mathrm{GPa})\end{array}$ & 34.61 & 30.72 & 35.41 \\
$\begin{array}{l}\text { Poisson's ratio } \\
\text { Shear modulus (GP) }\end{array}$ & 0.28 & 0.21 & 0.27 \\
$\begin{array}{l}\text { Compressive strength } \\
\text { (MPa) }\end{array}$ & 13.52 & 11.99 & 13.91 \\
$\begin{array}{l}\text { Flexural strength } \\
\text { (MPa) }\end{array}$ & 11.31 & 34.05 & 38.21 \\
$\begin{array}{l}\text { Tensile strength } \\
\text { (MPa) }\end{array}$ & 3.15 & 11.29 & 10.95 \\
Porosity & 11.27 & 1.71 & 1.51 \\
\hline
\end{tabular}

where $\rho\left(\mathrm{g} / \mathrm{cm}^{3}\right)$ is density, $\mu(\mathrm{GPa})$ is modulus of Coulomb (shear modulus), $K(\mathrm{GPa})$ is modulus of compressibility, $E$ $(\mathrm{GPa})$ is Young's modulus, and $v$ is Poisson's ratio.

The degradation of MPC and MCC by immersion in chemical solutions was estimated from the variation of the elastic characteristics as a function of immersion time. The tests are conducted on discs of $10 \mathrm{~mm}$ thickness cut from cylindrical specimens $(40 \times 80 \mathrm{~mm})$ of casted mortars. The damage parameter was calculated according to

$$
D_{E}=\frac{E(t)-E(0)}{E(0)},
$$

where $E(0)$ is the modulus of elasticity of the microconcrete before immersion and $E(t)$ is the modulus of elasticity of the microconcrete after a period $(t)$ of immersion.

The moduli of elasticity decrease after the immersion of MCC and MPC in the acid solutions (Figure 6). The exposure to the selected acid solutions affects more significantly MCC than MPC. On the other hand, it appears that the exposure of MPC to hydrochloric acid solution generates a substantial degradation by comparison to the other acid solutions. The introduction of calcareous filler seems to have beneficial effect on the resistance of MPC to acid attack.

The MCC specimens dedicated to the measurements of ultrasonic waves propagation velocities were so damaged by immersion to hydrochloric acid that cutting out discs from cylindrical samples cannot be done. Indeed a porous thick degraded layer of low mechanical strength is formed making it impossible to conduct tests and therefore to have data.
5.2. Compressive Strength. The cubic specimens were tested up to failure at loading rate of $1.25 \mathrm{~mm} / \mathrm{min}$ according to the RILEM CPT PCM-8 standard test method [16]; each test was repeated at least six times. The degradation of MPC and MCC by immersion in chemical solutions was estimated from the variation of the compressive strength as a function of immersion time. The relative variation of the compressive strength was calculated according to

$$
D_{\sigma_{c}}=\frac{\sigma_{c}(t)-\sigma_{c}(0)}{\sigma_{c}(0)},
$$

where $\sigma_{c}(0)$ and $\sigma_{c}(t)$ are the compressive strengths of the microconcrete before immersion and after a period $(t)$ of immersion, respectively.

The compressive strength of the three microconcretes has been affected by their immersion in the both acid solutions (Figure 7). However, it can be observed that the induced degradation is more important for MCC than MPC. Similarly, it is clear that hydrochloric acid is more aggressive than citric acid and its effects are more significant for MCC. The compressive damage parameter seems a significant indicator to measure the degradation by acid attack. The compressive strength of MCC was diminished by about 43\%, 68\%, and $79 \%$ after 14 days of exposure to citric, sulfuric, and hydrochloric acids, respectively, while a loss of $38 \%, 46 \%$, and $24 \%$ is recorded after 6 months of exposure of MPCc to citric, sulfuric, and hydrochloric acids, respectively. Adding calcareous fillers improves the resistance of micropolymer concretes to citric and sulfuric acids while no significant effects are observed when MPC are exposed to hydrochloric acid.

5.3. Flexural Strength. The results of the three-point bending up to failure are illustrated in Figure 8. The damage parameters $D_{\sigma_{f}}=\left(\sigma_{f}(t)-\sigma_{f}(0)\right) / \sigma_{f}(0)$ related to the relative variation of the flexural strength are reported as a function of the exposure duration. A decrease in the flexural strength is observed for all formulations. This decrease is more significant for MCC than for MPC for both chemical solutions. Furthermore, it appears that hydrochloric acid is more aggressive than the citric acid and its effect is more important for MCC. Indeed, the bending strength of the MCC was approximately decreased 65\% and 98.5\% after 14 days and 6 months of their immersion in hydrochloric acid. In addition, the hydrochloric acid leads to a degradation of MPCm greater than this of MPCc for the same immersion time. Hence, the introduction of calcareous fillers into the formulation involves further degradation of the micropolymer concrete when exposed to hydrochloric acid. In contrast, 

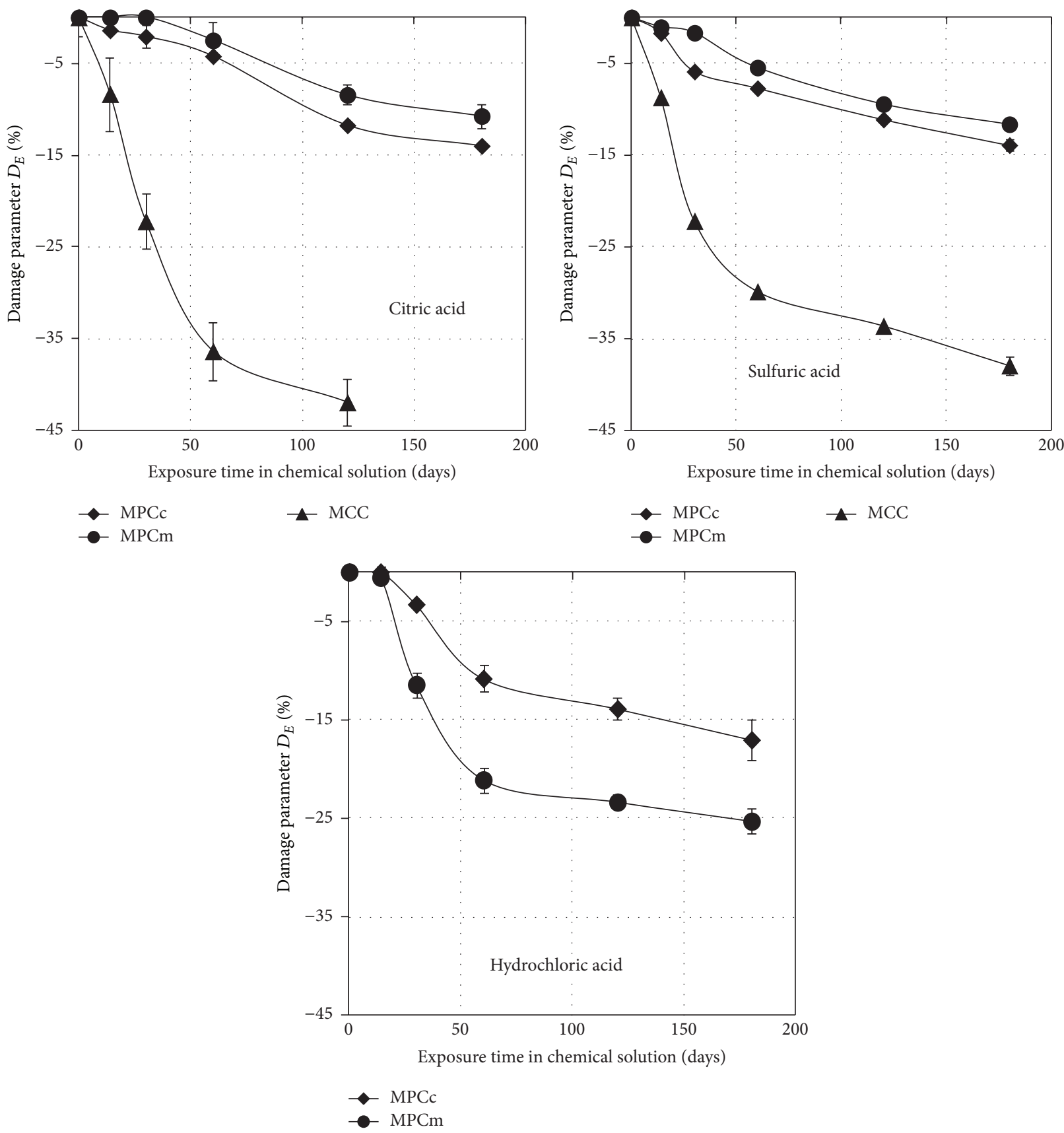

FIGURE 6: Evolution of modulus of elasticity as a function of exposure duration.

the introduction of limestone fillers improves the resistance of micropolymer concrete to chemical attack by citric acid while it has no effects on the resistance of MPC to sulfuric acid.

5.4. Discussion. The results from the compressive, the threepoint bending, and the ultrasonic wave's propagation tests conducted on microconcretes after their immersion to the selected three acid solutions suggest that the most relevant damage indicator is related to the compressive strength (Table 7). The cementitious mortars are less resistant to acid attack than polymer ones. Adding calcareous fillers improves or at least does not affect epoxy micropolymer concrete resistance to citric and sulfuric acids. However the resistance of epoxy micropolymer concretes to hydrochloric acid decreases by the incorporation of calcareous fillers.

\section{Physical Properties of Microconcretes Exposed to Acid Solutions}

To explain the loss of mechanical properties of microconcretes, the mass change was followed and visual observations were conducted during the exposure duration. FTIR analysis was conducted to corroborate the obtained findings. 

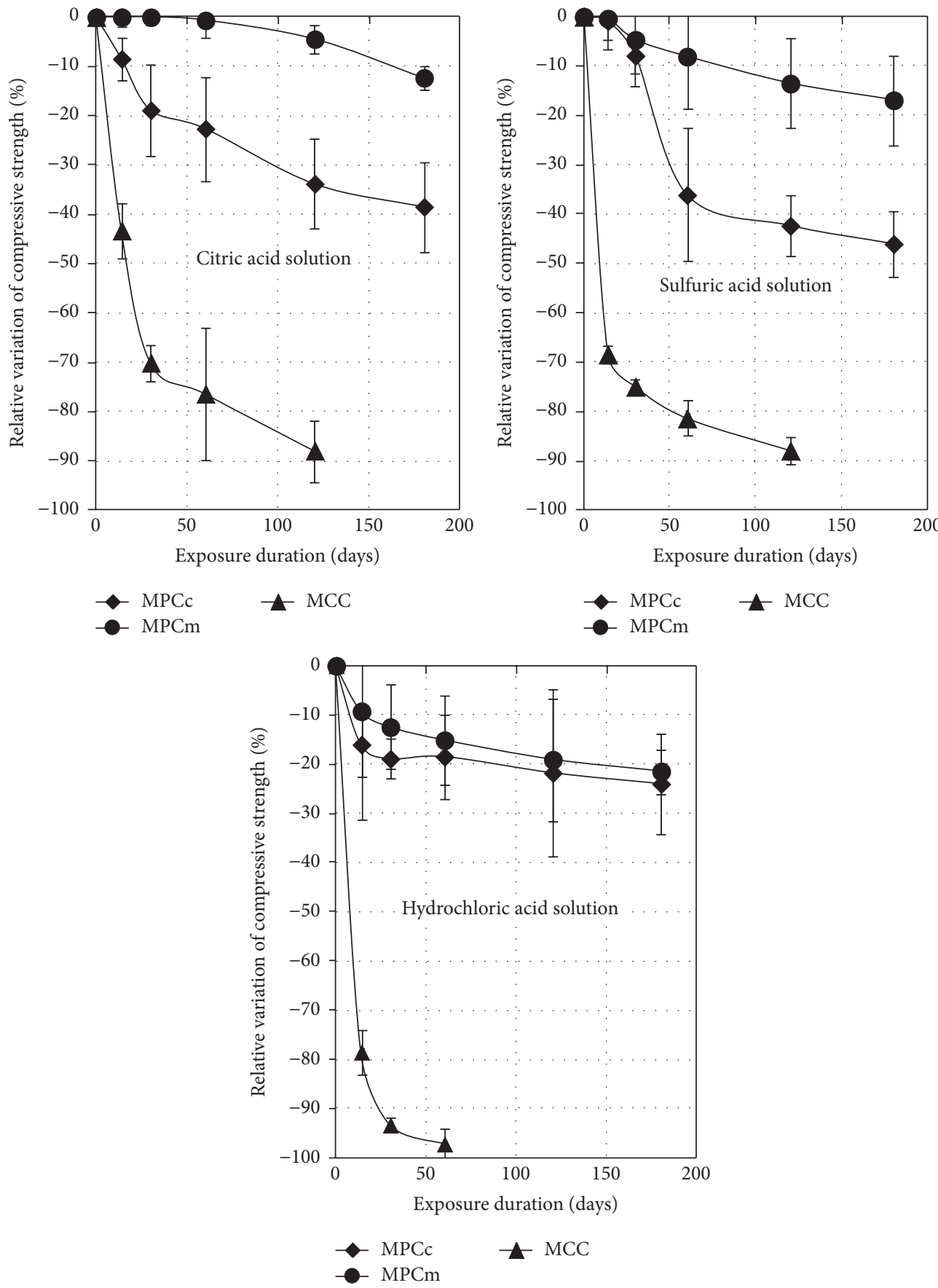

FIGURE 7: Evolution of the damage parameter related to compressive strength, $D_{\sigma_{c}}(\%)$.

TABLE 7: Different indicators of the degradation of the selected microconcretes.

\begin{tabular}{lccccccrrr}
\hline $\begin{array}{l}\text { Chemical solution } \\
\text { Microconcrete }\end{array}$ & \multicolumn{3}{c}{ Hydrochloric acid } & \multicolumn{3}{c}{ Sulfuric acid } & & \multicolumn{2}{c}{ Citric acid } \\
MPC & MPCm & MCC & MPCc & MPCm & MCC & MPCc & MPCm & MCC \\
$D_{\sigma_{f}}(\%)=\frac{\sigma_{f}(t)-\sigma_{f}(0)}{\sigma_{f}(0)}$ & -24 & -34 & -99 & -16 & -18 & -89 & -21 & -19 \\
\hline$D_{\sigma_{c}}(\%)=\frac{\sigma_{c}(t)-\sigma_{c}(0)}{\sigma_{c}(0)}$ & -24 & -22 & -100 & -46 & -17 & -100 & -38 & -12 & -100 \\
$D_{E}(\%)=\frac{E(t)-E(0)}{E(0)}$ & -17 & -26 & - & -14 & -12 & -38 & -14 & -11 & -55 \\
\hline
\end{tabular}



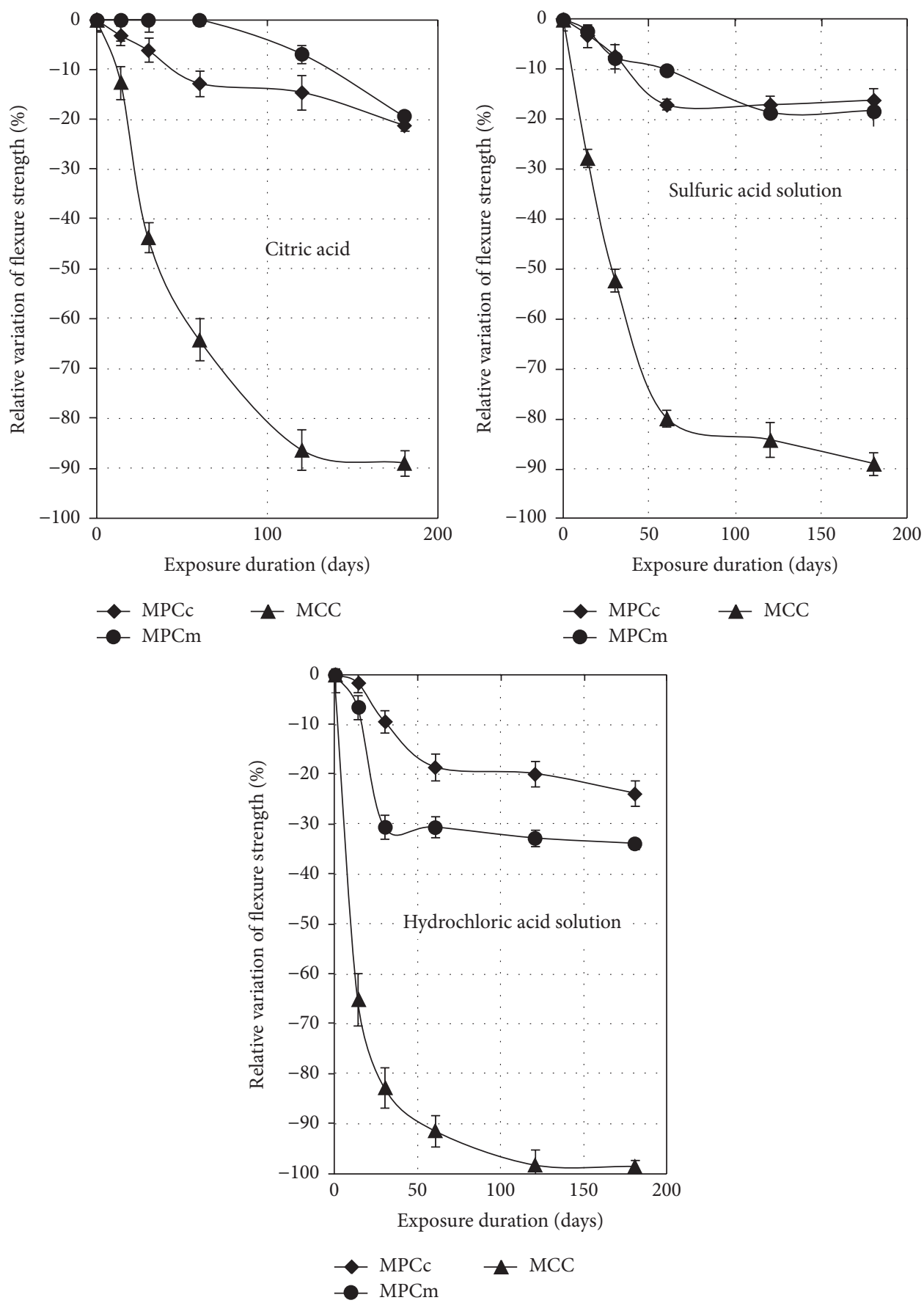

FIGURE 8: Relative variation of flexural strength as a function of immersion time.

6.1. Mass Change and Visual Observations. Figures 9, 10, and 11 illustrate the mass change of the different formulation exposed to citric, hydrochloric, and sulfuric acids, respectively, as a function of immersion time. A slight weight gain after the immersion of MPCc and MPCm to the considered acid solutions can be observed. This is attributed to water uptake, water used in the acid solutions. No dimensional change was noticed for immersion duration less than 6 months. The MPC is resistant to hydrochloric, sulfuric, and citric acids in regard to this parameter and for durations less than 6 months. Contrarily, MCC lost 10\% of its initial mass after six months of immersion in hydrochloric acid (Figure 10) while a loss of $92 \%$ is recorded when it is exposed to citric acid for the same duration (Figure 9) and 35\% when it is exposed to sulfuric acid (Figure 11). The immersion of microcement concrete, MCC, in acid solutions leads to a relevant degradation of MCC estimated throughout an important mass loss explaining the decrease of the mechanical characteristics. This degradation is accompanied by a material loss more important for MCC exposed to citric acid (Figure 12). 

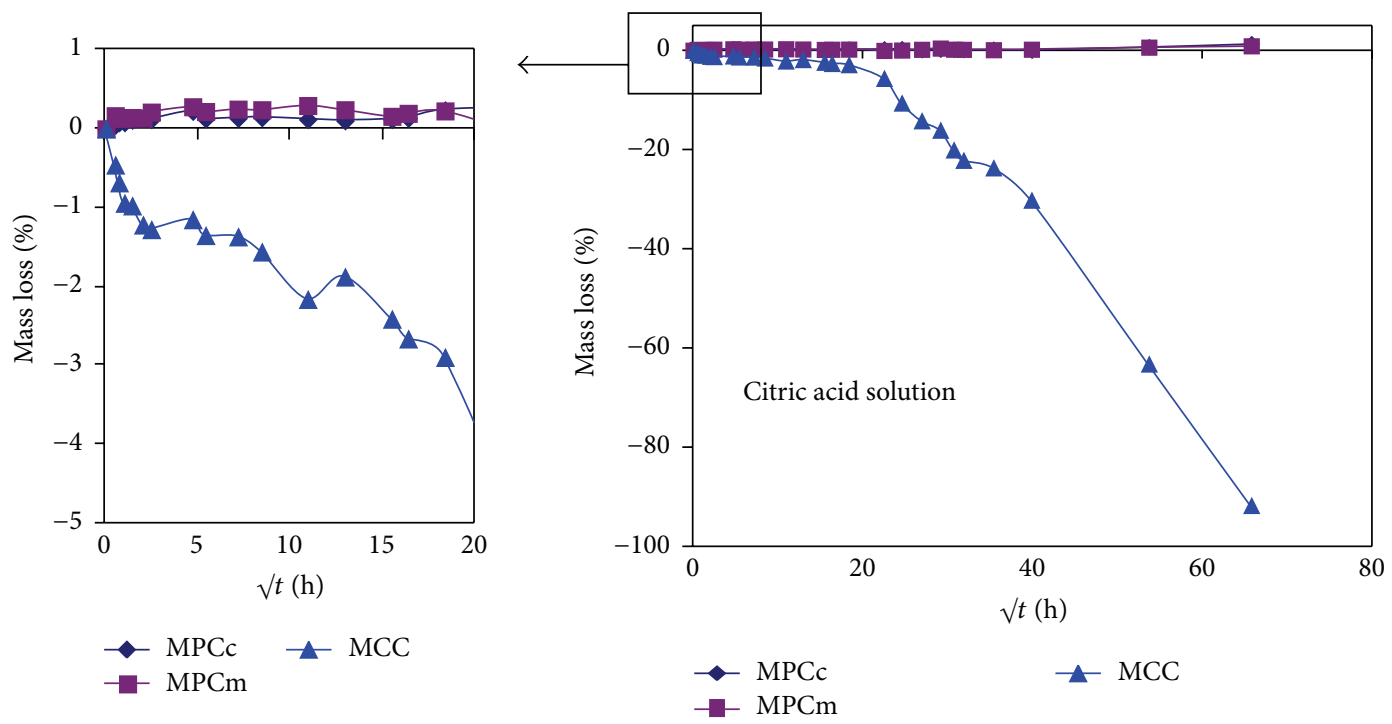

FIGURE 9: Mass change of microconcretes due to the immersion in citric acid.
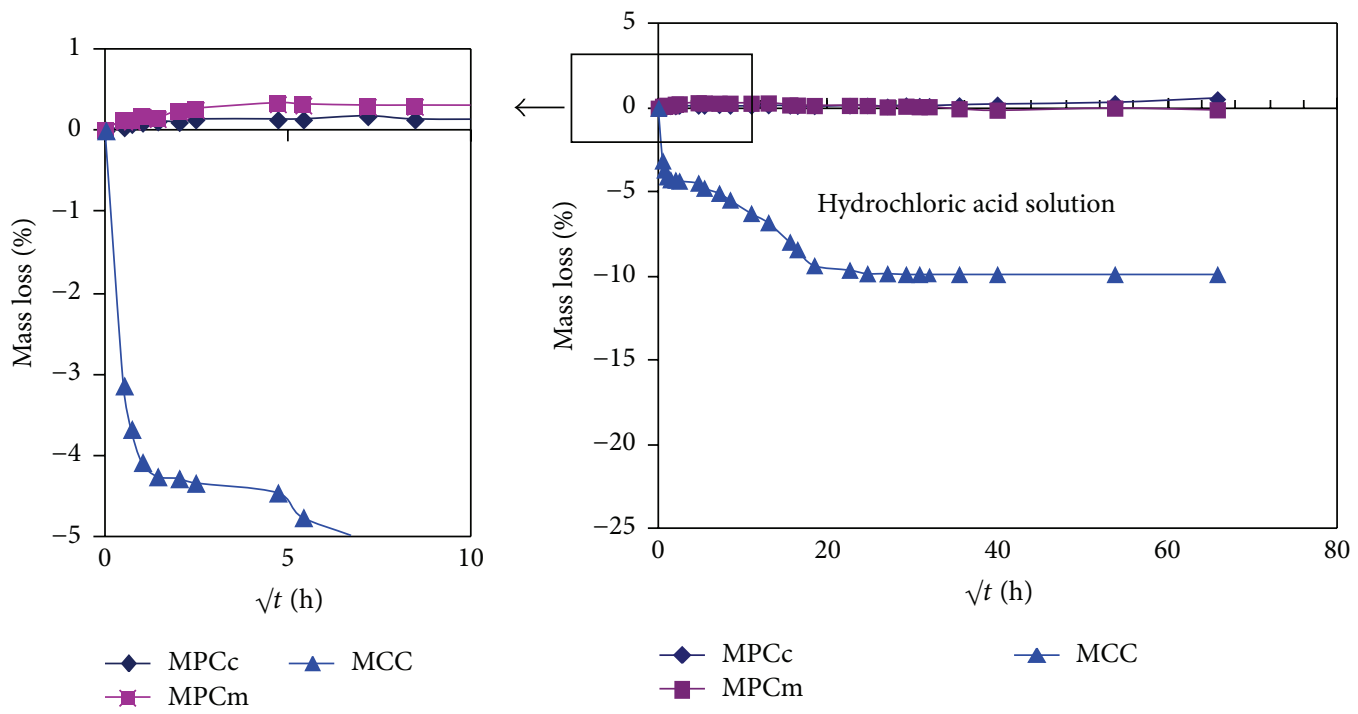

FIGURE 10: Mass change of microconcretes due to the immersion in hydrochloric acid.

The mass change is linked to material loss and to the formation of a degraded layer as observed in Figure 12. Visual analysis (Figure 12) leads to the following conclusions:

(i) The exposure of MPC to hydrochloric acid $(\mathrm{HCl})$ does not induce any visual degradation while a highly porous substance with yellowish coloration is observed for MCC. This substance is attributed to the dissolution of the calcium hydroxide, $\mathrm{Ca}(\mathrm{OH})_{2}$, and to the attack of the calcium silicate hydrate phases, C-S-H [17] $2 \mathrm{HCl}+\mathrm{Ca}(\mathrm{OH})_{2} \Rightarrow \mathrm{CaCl}_{2}+2 \mathrm{H}_{2} \mathrm{O}$. The initial dissolution of calcium hydroxide $\mathrm{Ca}(\mathrm{OH})_{2}$ leads to an increase in $\mathrm{Si} / \mathrm{Ca}$ and consequently to the modification of C-S-H phases that become denser and polymerize. Hence, the reported mass loss is less significant when MCC is exposed to hydrochloric acid
$(\mathrm{HCl})$, while the different indicators of degradation are higher (Table 7). Such degradation is revealed by the formation of a porous thick layer without an obvious dimensional variation (Figure 12). This porous degraded layer is of low mechanical strength leading to an important decrease of the mechanical properties of MCC. Moreover, the dissolution of cement hydrates containing $\mathrm{Ca}$ releases ions $\mathrm{Fe}^{3+}$ and sulfates. When diffusing into MCC Fe ${ }^{3+}$ causes the precipitation of ferric hydroxides and ettringite explaining the yellow color observed in the formed porous thick layer [20-22].

(ii) The sulfuric acid, $\mathrm{H}_{2} \mathrm{SO}_{4}$, is a very aggressive compound for cement concrete [18]. Indeed, its high acidity ( $\mathrm{pH}$ values often lower than 1) induces the 

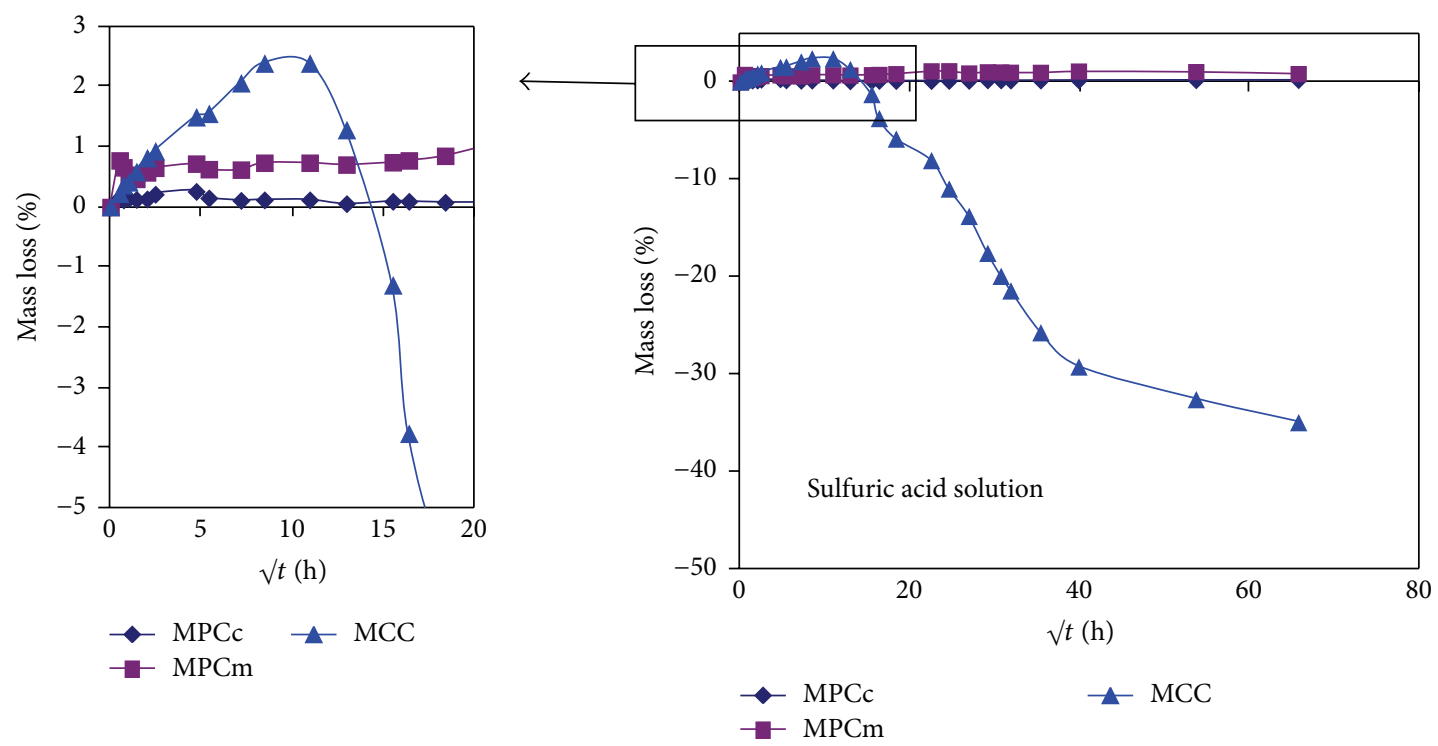

FIGURE 11: Mass change of microconcretes due to the immersion in sulfuric acid.

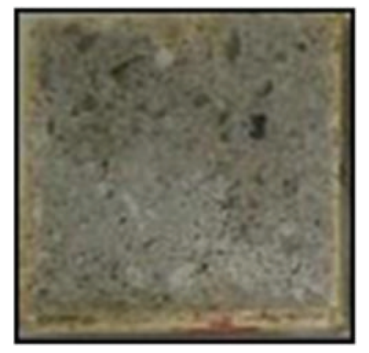

Hydrochloric acid solution
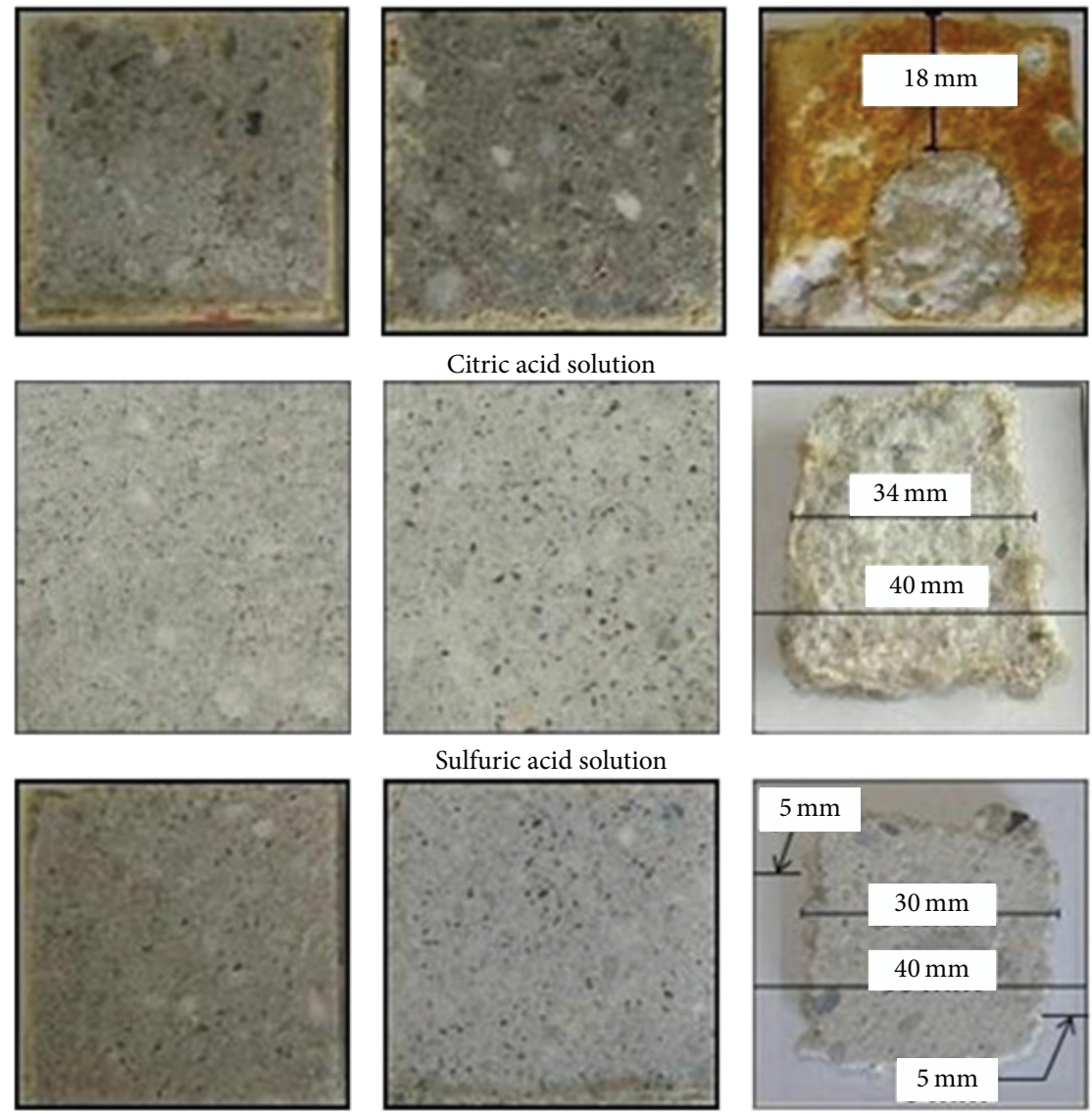

Sulfuric acid solution
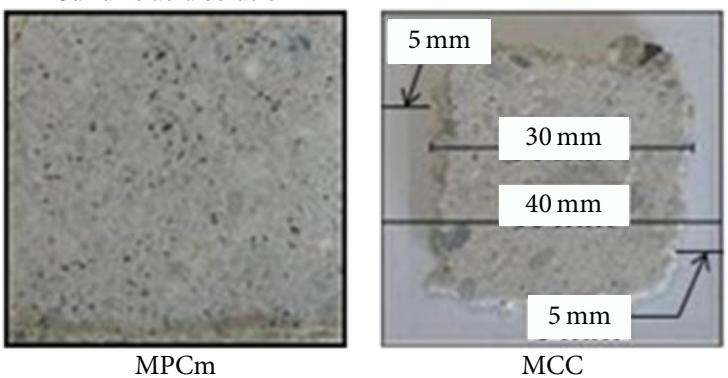

FIGURE 12: Visual degradation of the microconcretes after 60 days of immersion in acid solutions. 
TABLE 8: Characteristic bands of MPC observed with FTIR spectra.

\begin{tabular}{lccc}
\hline Band $\left(\mathrm{cm}^{-1}\right)$ & Assignment & Group & $\mathrm{MPCc}$ \\
\hline 1436 & C-O stretching & $\mathrm{CO}_{3}{ }^{2-}$ of calcite & \\
1180 & C-O stretching & Aromatic ring of DGEBA & $\times$ \\
1079 & Si-O-Si stretching & Quartz & $\times$ \\
1057 & C-H bending & Aromatic rings & $\times$ \\
877 & C-O stretching & $\mathrm{CO}_{3}{ }^{2-}$ of calcite & $\times$ \\
$777-778$ & Si-O bending & Quartz & $\times$ \\
694 & C-H out of plan bending & Aromatic rings & $\times$ \\
\hline
\end{tabular}

dissolution of cement hydrates and the formation of gypsum: $\mathrm{H}_{2} \mathrm{SO}_{4}+\mathrm{Ca}(\mathrm{OH})_{2} \Rightarrow\left(\mathrm{CaSO}_{4} ; 2 \mathrm{H}_{2} \mathrm{O}\right)$. These phenomena explain the mass loss and the observed dimensional variation.

(iii) The citric acid reacts with several cement hydrates (portlandite, C-S-H, ...) to produce calcium and aluminum salts. The damaged area shows a high porosity. The cementitious matrix degradation is mainly due to the progressive and almost complete decalcification as well as to the dissolution of all crystallized phases (hydrated and anhydrous components). This explains the observed mass loss and dimensional variations of MCC [19]. Equations describing the formation of calcium salts and aluminum salts due to the chemical reaction between the citric acid with the different cement hydrates are

$$
\mathrm{C}_{6} \mathrm{H}_{8} \mathrm{O}_{7}+\left|\left\{\begin{array}{c}
(\mathrm{CaO})_{1.7}\left(\mathrm{SiO}_{4}\right)\left(\mathrm{H}_{2} \mathrm{O}\right)_{4} \\
\mathrm{Ca}(\mathrm{OH})_{2} \\
3 \mathrm{CaO} \mathrm{Al}_{2} \mathrm{O}_{3} 3 \mathrm{CaSO}_{4} \cdot 32 \mathrm{H}_{2} \mathrm{O}
\end{array}\right\}\right| \Longrightarrow
$$

calcium salts and aluminum salts.

6.2. IR Analysis. The FTIR spectra of micropolymer concretes (MPCc and MPCm) before exposure to acid solutions are dominated by the vibration bands characterizing the siliceous aggregates as well as fillers present in the crosslinked epoxy polymer. Their characteristic bands are located at 1079 and $778 \mathrm{~cm}^{-1}$.

The IR spectrum of MPCm presents peaks at $1436 \mathrm{~cm}^{-1}$ and $877 \mathrm{~cm}^{-1}$ attributed to the calcite, main mineral existing in calcareous fillers. Moreover, it can be observed that IR spectra display peaks which may be attributed to the crosslinked epoxy: at 1,182 $\mathrm{cm}^{-1}[20,21], 1057 \mathrm{~cm}^{-1}$, and $694 \mathrm{~cm}^{-1}$. Assignment of the bands in the FTIR spectra of MPCc and MPCm before exposure to acid solutions is summarized in Table 8 .

The characterization of peaks present in the MCC IFRT spectra was achieved through the work [22]. The peaks observed in the $900-1200 \mathrm{~cm}^{-1}$ interval correspond to absorption bands, of calcium silica hydrate C-S-H products. However, ettringite (AFt) and monosulphate (AFm) display absorption bands in this interval. An attempt of the ascription of the observed IR absorption bands is given in Table 9.
TABLE 9: Characteristic FTIR bands before chemical attack.

\begin{tabular}{lcc}
\hline Band $\left(\mathrm{cm}^{-1}\right)$ & Assignment & Cement hydrate \\
\hline 1472 & O-H bending & Portlandite $\mathrm{CH}$ \\
1086 & S-O stretching & $\mathrm{SO}_{4}{ }^{2-}$ sulfate ions \\
1046 & Si-O stretching & Calcium silicate hydrate C-S-H \\
875 & Al-O-H bending & Ettringite AFm \\
778 & Si-O-Al bending & AFt, AFm \\
680 & $\mathrm{Al}-\mathrm{O}$ & $\mathrm{AlO}_{4}$ \\
\hline
\end{tabular}

Infrared analyses were conducted on the samples before and after aging by immersion in acid solutions during 6 months. The analysis was made on the degraded area. The following can be observed:

(i) The hydrochloric acid does not affect chemical bonds of both polymer microconcretes, MPCc and MPCm (Figures 13 and 14). However, for MPCm, a slight decrease of the intensity bands of the groups $\mathrm{C}-\mathrm{O}$ and $\mathrm{O}-\mathrm{H}$ (located at $1079 \mathrm{~cm}^{-1}$ ) associated with calcite characterizing limestone fillers can be noticed while no change is observed for MPCc. On the other hand, the analysis of MCC infrared spectra corroborates the hypothesis of the modification of C-S-H phases that polymerize by the appearance of vibration bands attributed to the presence of $\mathrm{C}-\mathrm{S}-\mathrm{H}$ corresponding to stretching $\mathrm{O}-\mathrm{H}$ groups at $3382 \mathrm{~cm}^{-1}$ and bending $\mathrm{O}-\mathrm{H}$ groups occurring at $1632 \mathrm{~cm}^{-1}$ (Figure 15). In addition the characteristic band of portlandite located at $1472 \mathrm{~cm}^{-1}$ completely disappeared. These results corroborate visual observations and validate mechanical results.

(ii) The sulfuric acid does not involve changes in the chemical structure of polymer concretes (Figures 13 and 14). However, the analysis of MCC infrared spectra reveals the disappearance of characteristic bands associated with calcium silicate hydrates phases C-S$\mathrm{H}$ (Si-O groups) located at $1086 \mathrm{~cm}^{-1}$, characteristic bands of ettringite located at $876 \mathrm{~cm}^{-1}$ related to $\mathrm{S}$ $\mathrm{O}$, and net decrease characteristic bands of portlandite situated at $1472 \mathrm{~cm}^{-1}$ linked to $\mathrm{O}-\mathrm{H}$ chemical groups of aluminates (Figure 15). This validates the hypothesis according to which chemical reactions between the sulfuric acid and the various cement hydrates (portlandite, C-S-H phases, and aluminates 

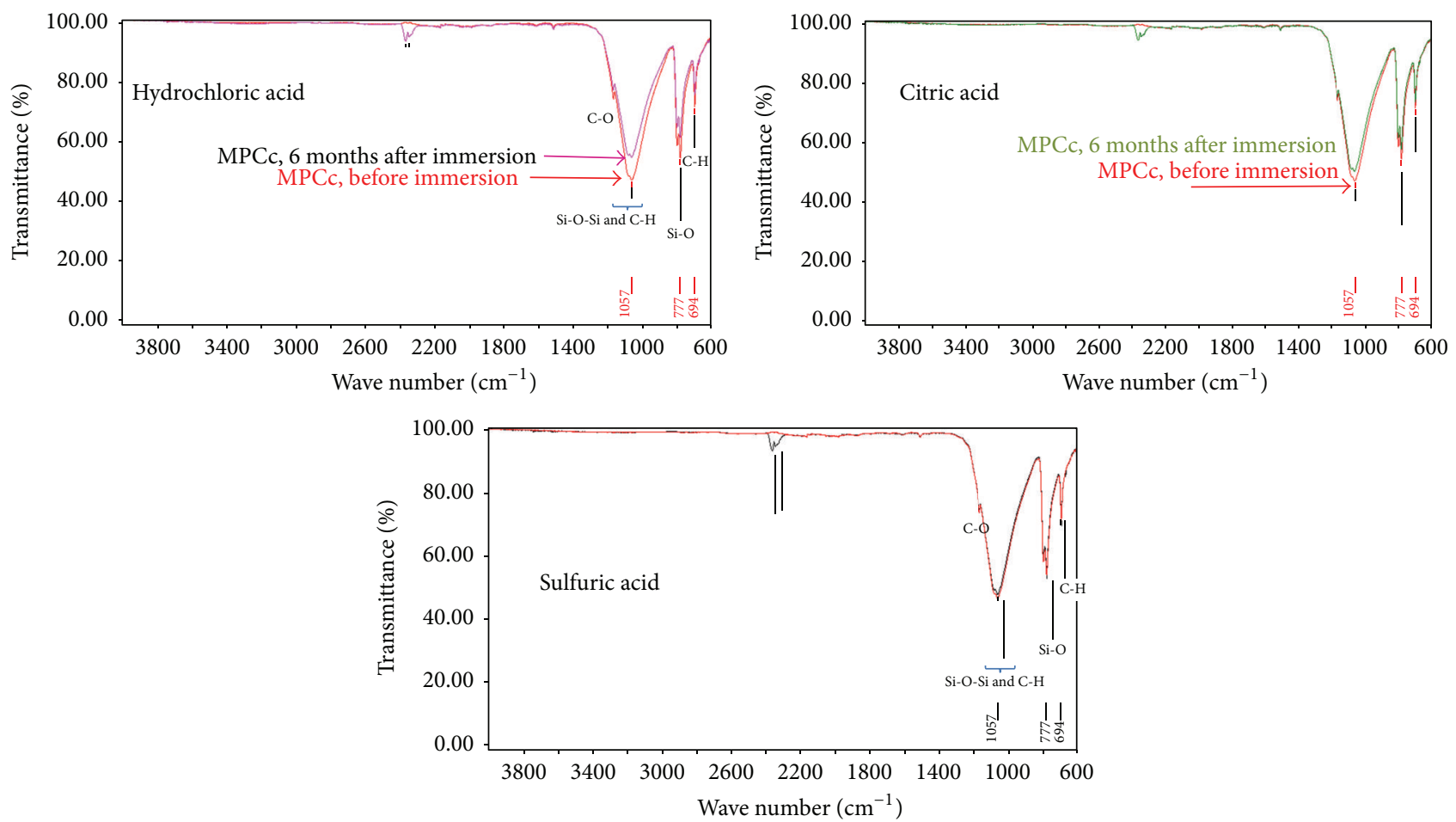

FIGURE 13: FTIR spectra of micropolymer concrete MPCc before and after 6 months of exposure to different selected acid solutions.
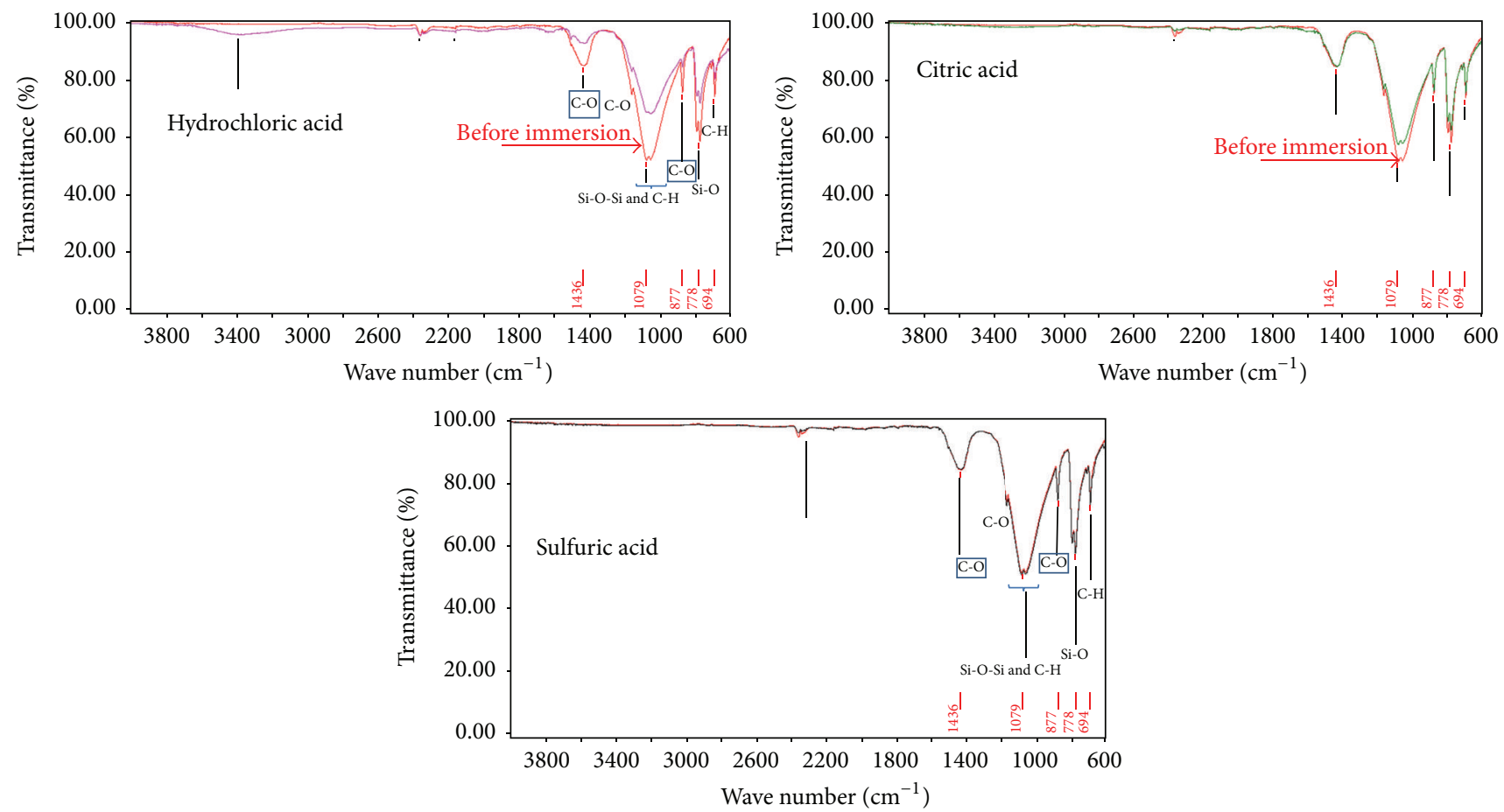

FIGURE 14: FTIR spectra of micropolymer concrete MPCm before and after 6 months of exposure to different selected acid solutions.

hydrates) cause the destruction of cement hydrates and therefore the material loss.

(iii) The citric acid does not affect the chemical bonds of the micropolymer concretes (Figure 13). For MPCm, a slight decrease is observed in the intensity of the peak linked to the stretching vibration "C-O" of calcite characterizing limestone fillers located at $1709 \mathrm{~cm}^{-1}$ (Figure 14). Analysis of the MCC infrared spectra 

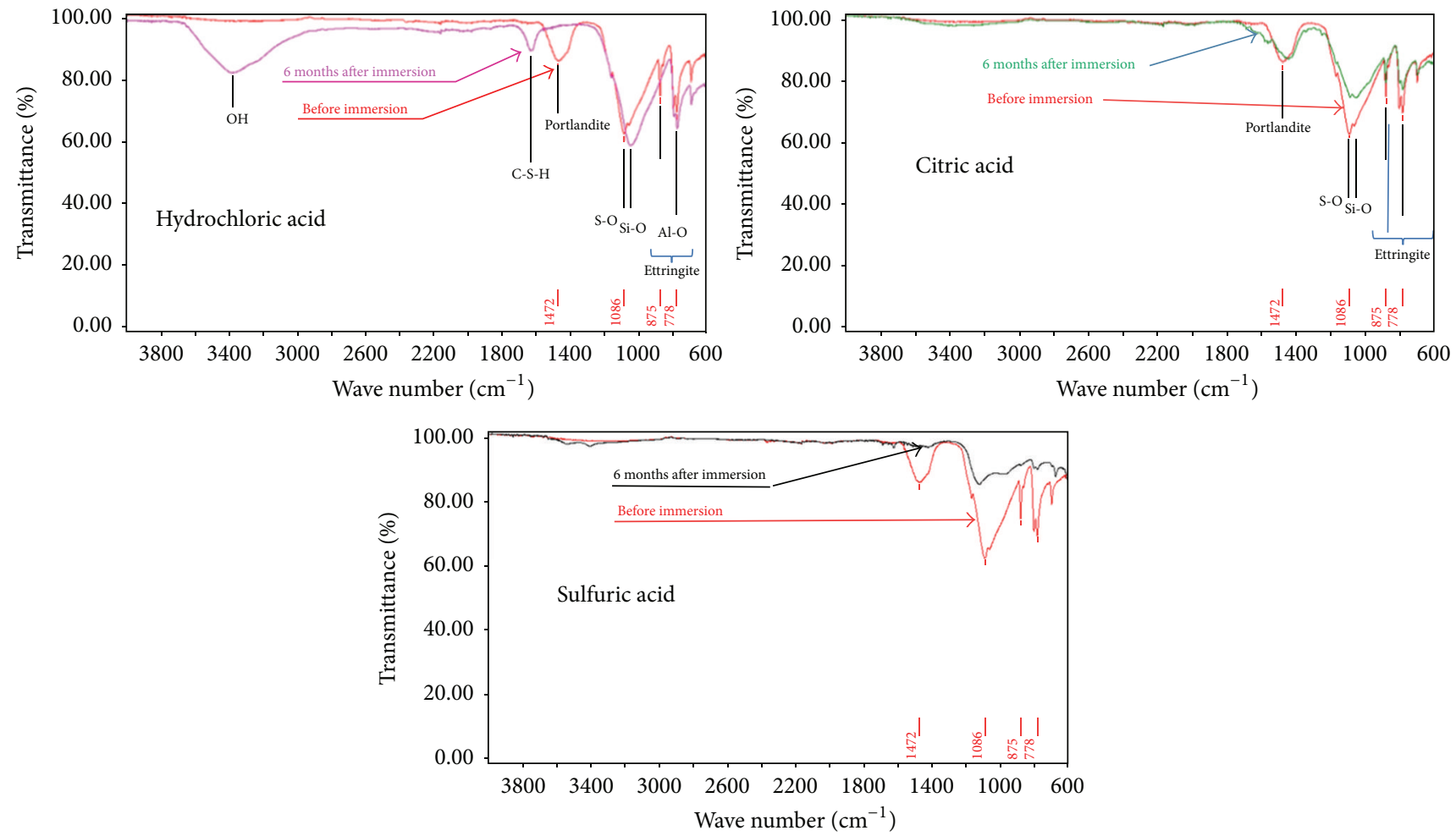

FIGURE 15: FTIR spectra of MCC before and after 6 months of exposure to the selected acid solutions.

reveals a significant decrease in the characteristic bands associated with calcium silicate hydrates phases C-S-H (the Si-O group) located at $1086 \mathrm{~cm}^{-1}$ and a shape change of characteristic bands of portlandite located at $1472 \mathrm{~cm}^{-1}$ and associated vibrations of the $\mathrm{OH}$ chemical groups (Figure 15). This confirms the hypothesis of degradation MCC by chemical reactions between citric acid with various cement hydrates (portlandite, C-S-H phases, and aluminates hydrates).

\section{Discussion and Conclusion}

In this work, the durability of micropolymer concrete (MPC) based on epoxy resin and microcement concrete (MCC) exposed to citric, sulfuric, and hydrochloride acids is studied. It appears that the best indicator to assess this type of degradation is the relative variation of compressive strength $D_{\sigma_{c}}$. Moreover, this work reveals that the MPC has a better resistance than MCC to chemical attack.

A small reduction in mechanical properties was observed after epoxy micropolymer concrete exposure to the selected acid solutions. The introduction of calcareous fillers into the formulation results in better mechanical characteristic but further degradation of the micropolymer concrete when exposed to hydrochloric acid. In contrast, it improves its resistance to chemical attack by citric and sulfuric acids. A mass change of all specimens is observed due to water uptake leading to the degradation in the resin-aggregates interface and therefore to the decrease of mechanical properties.
When immerged in citric and sulfuric acid solutions, the mass loss of MCC is associated with a more significant material loss than when it was exposed to hydrochloric acid. However, the degradation of MCC after its exposure to hydrochloric acid solution is more important than this observed after its immersion to citric acid solution due the chemical reactions leading to the formation of a thick porous layer. Hence, a significant decrease in MCC mechanical properties was highlighted due to the degradation and chemical cracking of the hydraulic cement binder.

\section{Competing Interests}

The authors declare that they have no competing interests.

\section{References}

[1] J. M. L. Reis and A. J. M. Ferreira, "The effects of atmospheric exposure on the fracture properties of polymer concrete," Building and Environment, vol. 41, no. 3, pp. 262-267, 2006.

[2] Y. Ohama, "Recent progress in concrete-polymer composites," Advanced Cement Based Materials, vol. 5, no. 2, pp. 31-40, 1997.

[3] J. M. L. Reis and A. J. M. Ferreira, "Assessment of fracture properties of epoxy polymer concrete reinforced with short carbon and glass fibers," Construction and Building Materials, vol. 18, no. 7, pp. 523-528, 2004.

[4] J. P. Gorninski, D. C. Dal Molin, and C. S. Kazmierczak, "Comparative assessment of isophtalic and orthophtalic polyester polymer concrete: different costs, similar mechanical properties 
and durability," Construction and Building Materials, vol. 21, no. 3, pp. 546-555, 2007.

[5] R. Bedi, R. Chandra, and S. P. Singh, "Mechanical properties of polymer concrete," Journal of Composites, vol. 2013, Article ID 948745, 12 pages, 2013.

[6] S. Mebarkia and C. Vipulanandan, "Mechanical properties and water diffusion in polyester polymer concrete," Journal of Engineering Mechanics, vol. 121, no. 12, pp. 1359-1365, 1995.

[7] M. C. S. Ribeiro, C. M. L. Tavares, and A. J. M. Ferreira, "Chemical resistance of epoxy and polyester polymer concrete to acids and salts," Journal of Polymer Engineering, vol. 22, no. 1, pp. 27-44, 2002.

[8] J. P. Gorninski, D. C. Dal Molin, and C. S. Kazmierczak, "Study of the modulus of elasticity of polymer concrete compounds and comparative assessment of polymer concrete and portland cement concrete," Cement and Concrete Research, vol. 34, no. 11, pp. 2091-2095, 2004.

[9] J. M. L. Reis, "Mechanical characterization of polymer mortars exposed to degradation solutions," Construction and Building Materials, vol. 23, no. 11, pp. 3328-3331, 2009.

[10] J. M. L. Reis, "Fracture assessment of polymer concrete in chemical degradation solutions," Construction and Building Materials, vol. 24, no. 9, pp. 1708-1712, 2010.

[11] M. Golestaneh, G. Najafpour, G. Amini, and M. Beygi, "Evaluation of chemical resistance of polymer concrete in corrosive environments," Iranica Journal of Energy \& Environment, vol. 4, no. 3, pp. 304-310, 2013.

[12] M. Heidari-Rarani, M. R. M. Aliha, M. M. Shokrieh, and M. R. Ayatollahi, "Mechanical durability of an optimized polymer concrete under various thermal cyclic loadings-an experimental study," Construction and Building Materials, vol. 64, pp. 308315, 2014.

[13] M. Martínez-López, G. Martínez-Barrera, L. C. S. Nunes, J. M. L. Reis, and H. S. da Costa Mattos, "Mixed mode fracture analysis in a polymer mortar using the Brazilian disk test," Engineering Fracture Mechanics, vol. 154, pp. 140-151, 2016.

[14] M. Haidar, E. Ghorbel, and H. Toutanji, "Optimization of the formulation of micro-polymer concretes," Construction and Building Materials, vol. 25, no. 4, pp. 1632-1644, 2011.

[15] RILEM CPT PC-2, "Method of making polymer concrete and mortar specimens," TC 113-CPT, RILEM, 1995.

[16] RILEM CPT PC-8, "Method of test for flexural strength and deflection of polymer-modified mortar," Technical Committee TC 113-CPT, RILEM, 1995.

[17] G. Xiong, Y. Cui, L. Chen, and H. Jiang, "Influence of hydrochloric acid etching on bond strength between concrete substrate and repair materials," Cement and Concrete Composites, vol. 26, no. 1, pp. 41-45, 2004.

[18] G. Arliguie and H. Hornain, Grandeurs Associées à la Durabilité des Bétons, GranDuBé, Presses de l'Ecole Nationale des Ponts et Chaussées, 2007.

[19] A. Bertron, G. Escadeillas, and J. Duchesne, "Cement pastes alteration by liquid manure organic acids: chemical and mineralogical characterization," Cement and Concrete Research, vol. 34, no. 10, pp. 1823-1835, 2004.

[20] A. Rigail-Cedeño and C. S. P. Sung, "Fluorescence and IR characterization of epoxy cured with aliphatic amines," Polymer, vol. 46, no. 22, pp. 9378-9384, 2005.

[21] N. B. Colthup, "Spectra-structure correlations in the infra-red region," Journal of the Optical Society of America, vol. 40, no. 6, pp. 397-400, 1950.
[22] R. Ylmén, U. Jäglid, B.-M. Steenari, and I. Panas, "Early hydration and setting of Portland cement monitored by IR, SEM and Vicat techniques," Cement and Concrete Research, vol. 39, no. 5, pp. 433-439, 2009. 


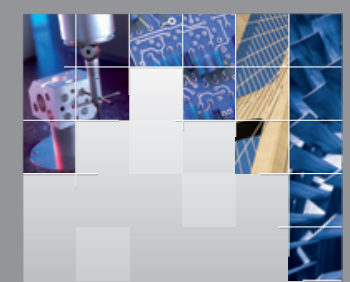

\section{Enfincering}
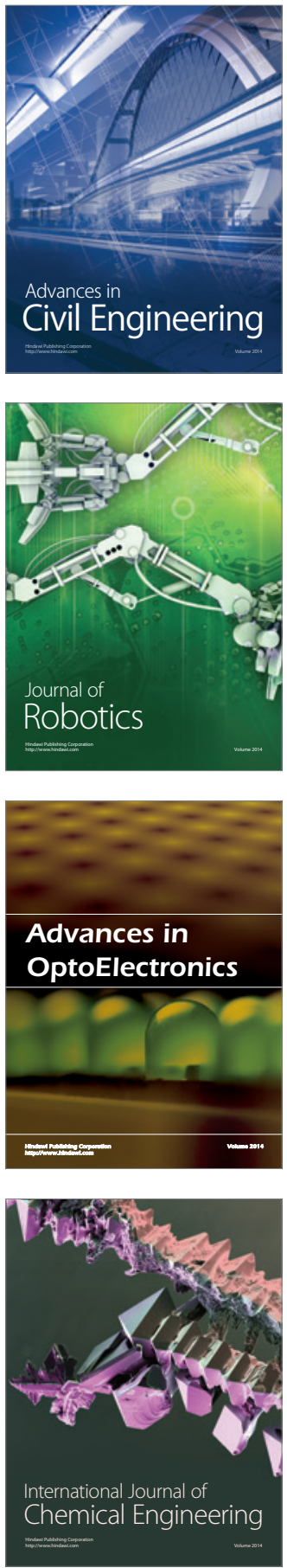

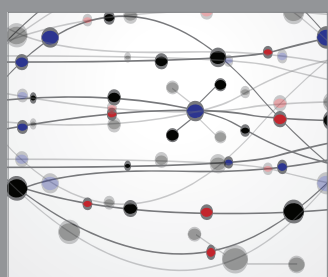

The Scientific World Journal

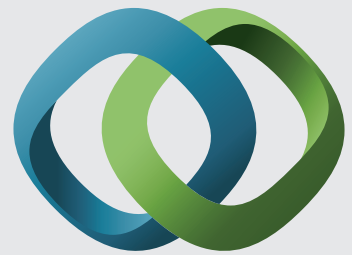

\section{Hindawi}

Submit your manuscripts at

http://www.hindawi.com
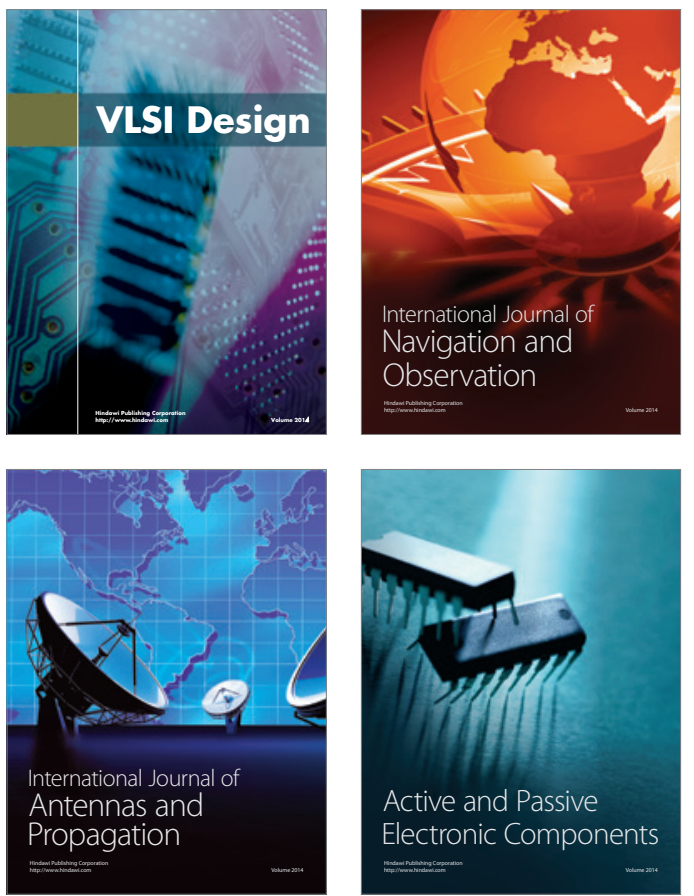
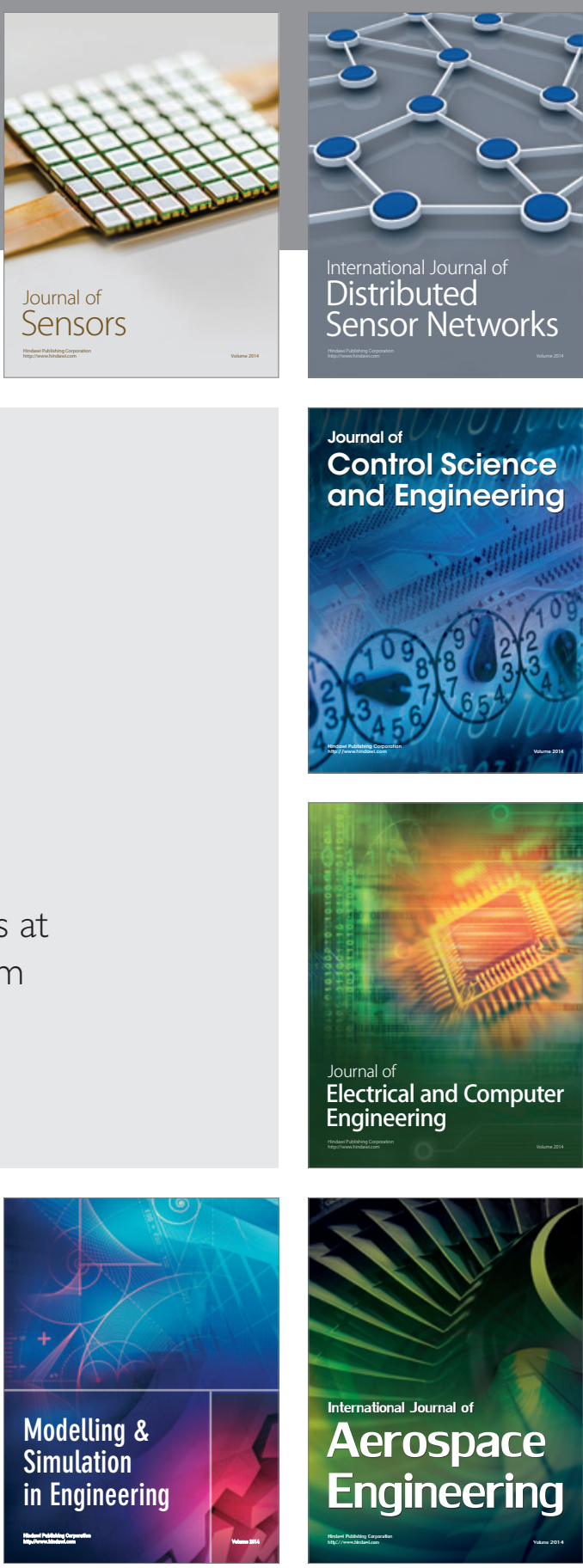

International Journal of

Distributed

Sensor Networks

Journal of

Control Science

and Engineering
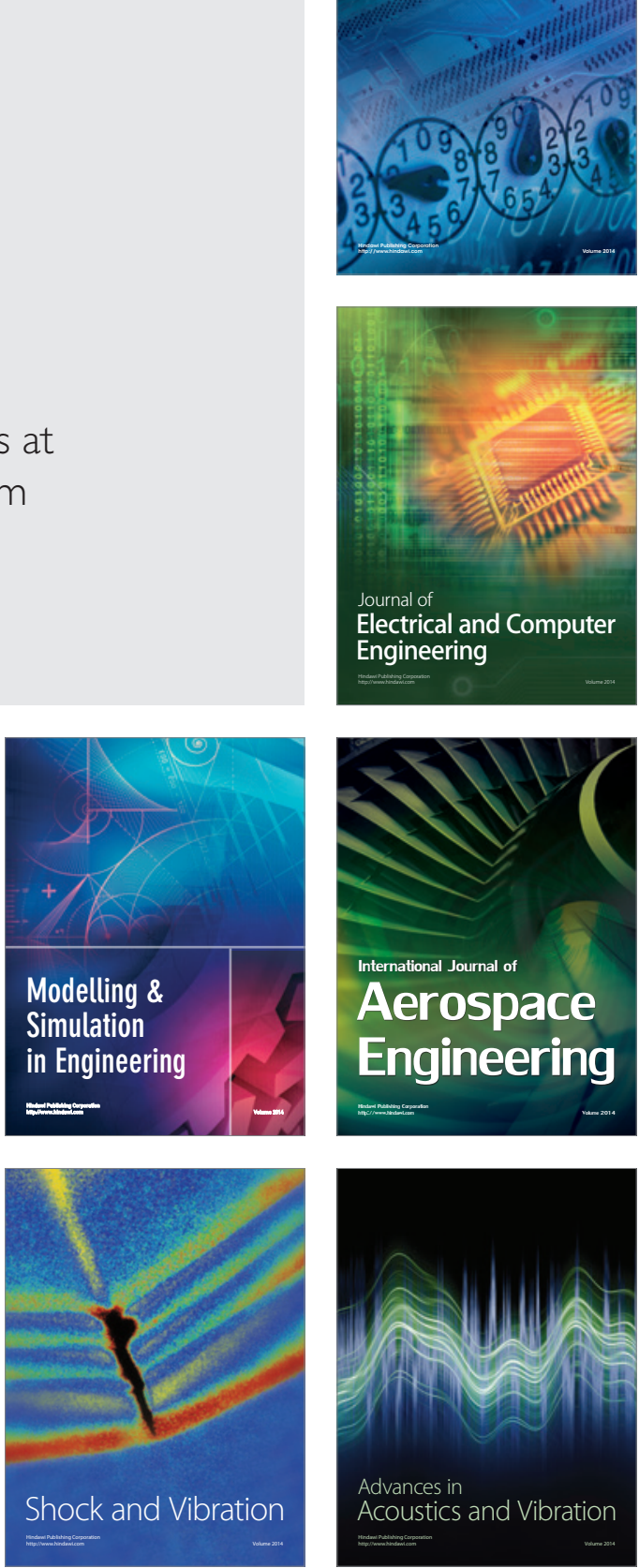